give a patient medication in his own home against his wishes, which I do not think is feasible. Before the professional staff can call such a Tribunal, it will be necessary to demonstrate that the patient's illness has been in existence for a minimum of three years and that it has been impossible to persuade him to take medication voluntarily.

The right to be medicated properly. I am amazed at the huge doses of neuroleptic drugs used by some colleagues and concerned that such a treatment section should not become a rogue's charter for overprescribing. I think that the amount of medication given and its regularity should be monitored by a second opinion doctor, as happens now when a patient is given medication against his wishes. It could be that over a period of time we could discover some upper limit to the injectable neuroleptics.

Yewcroft Mental Health Centre

Patricia A. J. Goodyear

Court Oak Road

Birmingham B179AB

\section{Social work liaison: facing a challenge}

\section{DEAR SIRS}

Recent government papers have suggested an integrated approach by local authorities and the health service to the care of the mentally ill outside hospitals. In the light of this, I would like to describe my experience, as a senior registrar, of providing a liaison group in a local authority social work team office which I ran for just over a year until September 1989.

The suggestion of some form of joint work originated from staff in the office and was discussed initially with the consultant psychiatrist at the nearby Day Hospital. Uncertainty surrounded the process of referral to the psychiatric service. The consultant suggested that urgent referrals could be seen at the day hospital within office hours. Less urgent cases may be suitable for discussion in a fortnightly liaison meeting which would discuss cases or issues of psychiatric relevance.

From an early stage, trained staff expressed difficulties in attending the meetings at the time specified and were often called out to other meetings, phone calls or to urgent difficulties in the office. Despite this, several interesting cases were brought to the meetings and discussed at length. However, as time went on, the problem of attendance worsened and it became clear that dissemination of information within the office was difficult.

New arrangements were made. The meeting times were changed and contact was made with the office ahead of the meeting. However, the new time was disastrous and we quickly reverted to the original time. Attempts to recruit from adjoining social work offices failed and after six months, the only regular attenders were trainees without a caseload of their own. Educational talks on issues such as ethnic minorities, violence, drug and alcohol abuse, etc. became the norm. The only trained staff member who attended began to use the meetings to discuss mental health officer work and the trainees, with little experience of the Mental Health Act, became increasingly excluded. In September 1989, I resigned from my commitment to the social work office, at the time of a move to another hospital. The psychiatrist registrar from the Day Hospital took over the meetings and has continued the link by providing regular seminars.

The White Paper on Community Care emphasises that effective liaison is necessary between local authorities and health services, particularly in areas where the distinction between health and social care is blurred. In the light of this, a regular link with an area social work office seems an ideal first step to develop relationships and to provide information on psychiatric illness and treatment, often a focus of concern to social workers. This link may also help to heal the philosophical and political rift so often felt to exist between the two professions. The difficulties experienced during this liaison group, despite enthusiasm on both sides, are worthy of comment. I became aware over the course of the year of the enormous pressure of work on trained social workers and the huge organisational problems within the office. Staff meetings had been abandoned and little in the way of timetabling and regular commitments could be achieved. One staff member explained that priorities were heaped on top of priorities and another described very long working days which were inadequately recognised or remunerated. In this setting, psychiatric aspects of social work were recognised and staff were keen to attend meetings but it proved impossible to find time to do so. Even the recognition of the meeting's importance by their regional manager produced no change. Crises could now be attended to by links with the local day hospital but a liaison meeting did not deal with crises and therefore other priorities took its place.

It was felt that a senior registrar in psychiatry could provide an autonomous service to a social work office and could offer flexibility of meeting times because of the supernumerary nature of the post. However, the provision of lectures and seminars under the auspices of a liaison meeting does not seem appropriate, nor does the informal supervision of a mental health officer.

Very little relevant literature exists on this approach to joint working. Grant \& Richardson (1988) and in Community Care (22.9.88) described a similar social work liaison group in Newcastle. The senior registrar involved fulfilled a wider role, taking part in joint evaluations of direct and urgent referrals. In the 
Glasgow group, referrals were directed to the appropriate medical staff as necessary. When the Newcastle group ended, in September 1988, there was concern that media interest in child abuse might cause difficulties. This was when our group started. I left as community care proposals were beginning to be discussed at local level.

In future, government policy may provide the impetus to effective liaison between local authorities and health service staff. Each will need the services and skills of the other. Joint meetings will no longer be seen as a valuable option but as a priority. This may be enhanced by the media turning from its focus on child abuse to that of community neglect of the mentally ill.

Clackmannan County Hospital

Alloa FK10 2BE

\section{Reference}

Grant, W. \& Richardson, A. (1988) A psychiatric liaison service for a social service office: an unmet need, a useful innovation or an unnecessary inconvenience? Psychiatric Bulletin, 12, 481-483.

\section{A social network in a psychogeriatric day hospital}

DeAR SIRS

I would like to describe the development of social network in a new psychogeriatric Day Hospital since its inception. Patients developed close ties with other patients or staff while in-patients which continued when they attended the day hospital.

The patients developed a small closely knit group at the day hospital and later kept in telephone contact, began to visit each other, and perform activities such as shopping, entertainment etc. together. If geographically separated they maintained letter or telephone contact. Despite the concept of confidentiality, a lot was learnt about patients who declined in their mental state or who defaulted from attendance, from other patients in this network.

Once discharged, patients often dropped in to visit fellow patients and staff. If a patient was readmitted to a psychiatric bed or elsewhere for medical reasons, other patients would visit him/her. The whole phenomenon evolved to include patient's relatives who often became closely involved in this network.

As many of the patients are single, separated or widowed, this social network, which was supportive and stabilising, persisted after discharge, perhaps indefinitely. It also enhanced compliance with treatment and made it easier to refer patients to other facilities away from the day hospital if their friends were already attending there.
Although the development of such a social network in a psychiatric day hospital has been reported (MacMillan \& Shaw, 1966) it appears to have been forgotten and not used to its fullest advantage.

Whittington Hospital
Dartmouth Park Hill

London N19 5HT

\section{References}

MacMillan, D. \& SHaw, P. (1966) Senile breakdown in standards of personal and environmental cleanliness. British Medical Journal, ii, 1032-1037.

\section{Psychiatrists in potentially dangerous situations}

\section{DeAR SiRS}

Dr Philip Marshall is to be congratulated on his courageous attempt to "talk down" a potential suicide threatening to jump from a high building (Psychiatric Bulletin, March 1991, 15, 147-148). I was quite horrified that Dr Marshall did not appear to be attached to the fire service platform, except by holding on to the rail "like grim death". Surely the fire service could have fitted him with a harness, such as is used by rock climbers, and belayed (secured) Dr Marshall to the platform with rope slings, karabiners, etc.

Had I been in Dr Marshall's position (literally and metaphorically), there is no way that I would have agreed to be lifted to lethal heights without such protection, even if I had to go home and collect my own rock climbing gear first!

Dr Marshall's account raises important questions about the extent to which psychiatrists should put themselves in physical danger at the request of outside agencies. I recently received a request from a GP to go to the home of a paranoid schizophrenic patient who was at the time threatening his brother and the police with a large knife. Not having the bravery of Dr Marshall, I am afraid I refused to attend the patient until he was disarmed and safely in police custody. Fortunately, the GP accepted my view that we should not put ourselves at risk unnecessarily; before our conversation, he had been willing to attend himself, taking with him his GP trainee.

It seems that from the first day at medical school, doctors are inculcated with the belief that they must offer help, whatever the circumstances, at whatever cost to themselves, their family and friends. The longer I practise medicine, the more inappropriate this seems, especially in a branch 